\title{
Principles for certain geomechanics problems solution during overworking of mine workings
}

\author{
Volodymyr Bondarenko ${ }^{1}$, Iryna Kovalevska ${ }^{1 *}$, Hennadii Symanovych ${ }^{2}$, Mykhailo Barabash ${ }^{3}$, and Ildar Salieiev ${ }^{4}$ \\ ${ }^{1}$ Dnipro University of Technology, Department of Mining Engineering and Education, 19 Dmytra Yavornytskoho Ave., Dnipro, 49005, \\ Ukraine \\ ${ }^{2}$ Dnipro University of Technology, Department of Labour Protection and Civil Safety, 19 Dmytra Yavornytskoho Ave., Dnipro, 49005 , \\ Ukraine \\ ${ }^{3}$ LLC “DTEK Energy”, Department on Coal Production, 57 Lva Tolstoho Str., Kyiv, 01032, Ukraine \\ ${ }^{4}$ PJSC "Donetsksteel” - Iron and Steel Works", 30 Lesi Ukrainky Blvd., Kyiv, 01133, Ukraine
}

\begin{abstract}
This paper deals with two relevant and interrelated directions of coal mining development. Firstly, the resource-saving complete extraction of reserves, and secondly, the intensification of mining activity through mining operations conducted on several seams. The objective of overworking of mine workings with a real representation of mining-and-geological and mining-engineering conditions has been formulated. Five peculiarities of the geomechanical models construction for overworking of mine works have been revealed and substantiated. The technology for performing a series of computational experiments is proposed. The task of the protecting pillar influence, which is located in overlying coal seam, on the state of mine working placed in the underlying coal seam has been solved. An optimal scheme for its maintenance is proposed.
\end{abstract}

\section{Introduction}

The research purpose relevance is conditioned by the necessity for geomechanical substantiation of various engineering decisions in mining the series of strata based on two main directions of coal mining development: resource-saving complete extraction of reserves due to their partial preparation in favourable mining-geological and mining-engineering conditions; intensification of mining activity through mining operations conducted simultaneously on several seams.

The term "complete extraction of reserves" means the extraction of various types of protecting pillars on the overlying horizons remaining after the transition of mining operations to the underlying horizons. These protecting pillars are to some extent delineated by mine workings, in which, from one side, a mined-out space (after the stope works of previous periods) with a consolidated massif of previously collapsed rocks is located. The mechanical properties of such rocks are essentially different from the holistic massif, which, according to studies [1-5], leads to the "smoothing" of stresses, their more uniform distribution, which increases the stability of the noted delineating mine workings. Moreover, when mining protecting pillars, new anomalies of rock pressure will have a reduced intensity of action due to the damping properties of previously collapsed and consolidated rocks. The above trends as a whole contribute to lowering the costs for maintaining the mine workings delineating the pillar, if there is a necessity for their further use according to the mining plan. This is confirmed by a number of studies [6-9].
The technology of two or three coal seams joint mining has more widespread experience in practical implementation, for example, in the Western Donbas. This is conditioned by a motivation to radically increase the stope works intensity with the corresponding technical-and-economic benefits [10-16].

\section{Problem statement and solution}

Both resource-saving coal mining trends in terms of the parameters substantiation suggest the development of geomechanical models that differ by sufficient complexity and multifactority. Most mining-engineering situations under study require the spatial models construction in order to reflect mine workings network which includes, as a rule, stope and preparatory mine workings, having a mutually perpendicular direction. This is the first peculiarity of this class of problems.

The second peculiarity is the significant dimensions of geomechanical models, in which to achieve the required level of their adequacy and reliability of the results obtained, the following should be reflected:

- in a direction perpendicular to the longwall face length (it is denoted by the coordinate $X$ ), the frontal bearing pressure zone ahead of the stope face and the unloading zone behind it at distances that provide attenuation (or stabilization) of the stress-strain state components (SSS) to the level of the permissible error of their deviations; according to this condition, the considered direction should be not less than $X=120-150 \mathrm{~m}$;

- in a direction parallel to the longwall face length

\footnotetext{
* Corresponding author: kovalevska_i@yahoo.com
} 
(coordinate $Z$ ), at least half of its length should be placed, extraction mine working and part of the massif in the side opposite to the stope face to a width, which ensures the SSS components stabilization in the area of the model vertical bound; the massif texture is not essential here holistic or collapsed and consolidated rocks; the fulfilment of such a condition implies a model size not less than $150-180 \mathrm{~m}$, taking into account sufficiently symmetrical initial and borderline conditions relative to the axis $X$ located in the centre of the longwall face length, since with significant asymmetry the size $Z$ will have to be doubled;

- the model height (coordinate $Y$ ) should be chosen according to the reflection condition (with a certain margin) of all characteristic zones of rock pressure anomalies and the related texture transformations of the surrounding rock massif; in the coal seam roof, the model height should corresponds to the height of the frontal bearing pressure zone ahead of the longwall face with at least one-and-a-half margin for various SSS distortions types, conditioned by the vertical geostatic load application; behind the longwall face, in the mined-out space, three characteristic zones should be placed [2, 7, 18]: uncontrolled collapse, hinged-block displacement and smooth deflection of layers without discontinuity; in the seam bottom, also with a one-and-a-half fold margin, the zones of frontal bearing pressure and unloading are provided; meeting these conditions usually requires a model height of at least $60-80 \mathrm{~m}$; when modelling the joint mining of several coal seams, the height $Y$ should include all of the above elements for the upper seam in the roof and the lower seam in the bottom, plus the thickness of partings; here it is necessary to choose a height $Y$ for each specific case, but it definitely increases by 2 times or more.

The third peculiarity of the considered group of geomechanics tasks is the necessity to represent the mining operations consequences for the previous periods - it mainly relates to the development of previously left protecting pillars. Here it is necessary to take into account the parameters of residual rock pressure anomalies acting in the borders of the protecting pillars and the areas of the mined-out space contacting with them together with the delineating mine workings.

Existing studies [1, 2, 19-23], note a tendency toward a decrease in the activity of the rock pressure anomalies action over time $t$ that has passed since the end of the stope works. The parameters of anomalies in the borders of the protecting pillars substantially depend on the rheological phenomena of creep deformations and stresses relaxation; but there is one more important factor here - the process of shrinkage (consolidation) of previously collapsed rocks in the mined-out space under the geostatic pressure action. Experimental research on the process of rocks shrinkage in the uncontrolled collapse zone in the Western Donbas [19] show the development of this process to $45-55 \%$ of the initial height; at the same time, the resistance of consolidated rocks can increase to $10-15 \mathrm{MPa}$, which approximately corresponds to $40-60 \%$ of the compressive resistance of argillite and siltstones of the Western Donbas in the holistic state. Relative to the deformation modulus of collapsed and consolidated rocks, then (in accordance with experimental data) it increases from $5-10 \mathrm{MPa}$ in the initial stage of consolidation to $100-300 \mathrm{MPa}$ in the final stage of shrinkage development.

Thus, massif of collapsed and consolidated rocks over time $t$ becomes more rigid and more actively resists to the geostatic load. In qualitative terms, the tendencies in the influence of rheology and consolidation factors of collapsed rocks are shown in the scheme of Figure 1. Thus, at the end of the previous period of coal extraction (formation of a protecting pillar $t=t_{1}$ ), the vertical geostatic pressure $\sigma_{y}$ distribution corresponds to traditional concepts: from the side of the pillar, there is a lateral bearing pressure zone with concentration $\sigma_{y}$ of at least several units from the initial state $\sigma_{y}=\gamma H$ of virgin massif (where $\gamma$-weight-average unit specific gravity of rocks to depth $H$ of the pillar location). Above the mine working and from the side of the mined-out space, the component $\sigma_{y}$ sharply decreases with its gradual growth in the depth of the uncontrolled collapse zone. Then, over time $\left(t=t_{2}>t_{1}\right)$, the concentrations $\sigma_{y}$ in the border of the protecting pillar decrease, and from the side of the minedout space $\sigma_{y}$ grows near mine working due to the collapsed rocks consolidation and an increase in their resistance to the vertical rock pressure. After a long period of time $\left(t=t_{3}>t_{2}\right)$, usually calculated in years, the process of the so-called collapsed rocks consolidation is stabilized repulsing the rock pressure at the level of about half of the holistic rocks compressive resistance in the coal seam roof. This is usually quite enough to reach the initial state of virgin massif $\sigma_{y}=\gamma H$ : from the side of a pillar, the concentrations $\sigma_{y}$ in the larger zone of the lateral bearing pressure are maximally reduced, and from the side of the mined-out space, small concentrations $\sigma_{y}$ are formed near mine working (a kind of lateral bearing pressure zone). In general, rock pressure anomalies are "smoothed", which contributes to the increase in stability of delineating mine workings.

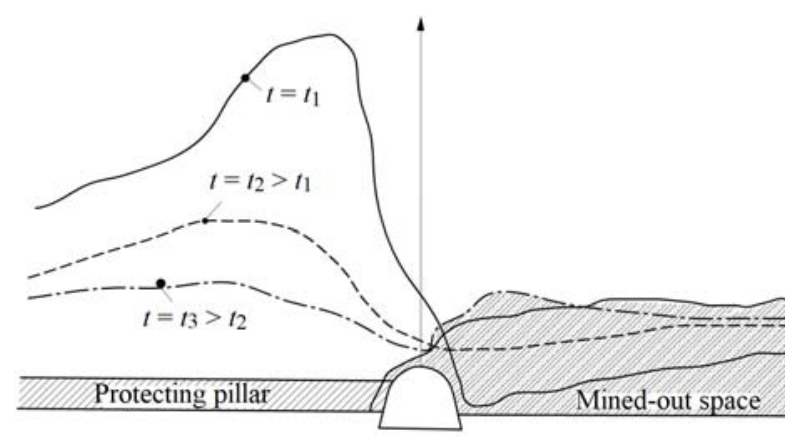

Fig. 1. Change in time $t$ of the vertical stresses $\sigma_{y}$ distribution near the border of the protecting pillar.

Such a mechanism for converting rock pressure anomalies after previous periods of stope works is expedient to be reflected in the geomechanical model at the last stage, that is, after a long period of time when the protecting pillar mining is planned. This process is taken into account by changing the mechanical characteristics of collapsed and consolidated rocks in accordance with their behaviour over a long period of time after disintegration. In the first approximation, for the Western 
Donbas conditions, it is recommended to accept the following mechanical characteristics of collapsed and consolidated rocks:

- compressive resistance $\sigma_{\text {compr }}$ in the range of $40-$ $60 \%$ of that for the holistic lithotype state;

- tensile strength $\sigma_{s t r}$ is practically absent; for unambiguous calculation procedure, $\sigma_{s t r} \leq 0.1 \mathrm{MPa}$ can be accepted;

- deformation modulus $E_{d}$ is accepted in the range of $5-10 \%$ of the value for the holistic lithotype.

The fourth peculiarity of the studied geomechanical problems class is the necessity to take into account the texture transformations of the adjacent rocks of the main roof (the so-called hinged-block displacement zone) that have occurred above the uncontrolled collapse zone in previous periods of stope works. Texture transformations in the hinged-block displacement zone signify the development (in the process of roof rock layers bending) of a system of predominantly vertically directed fractures that divide the lithotype into a series of rock blocks, from which a kind of thrust system is formed. It can lose stability at a certain value of the rock layer deflection, and, when the flexure strains are restricted (by means of a bearing from the side of underlying massif), this thrustblock system has a significant load-bearing capacity and actively resists to geostatic vertical rock pressure. The formation mechanism of thrust systems constituting the hinged-block displacement zone is described in sufficient detail in the works [19, 24-28], and the adequate reflection of this zone in models of this class of geomechanics problems is of great interest for us.

The importance of adequate hinged-block displacement zone modelling is determined by its significant influence on the displacement processes in the coal-overlaying formation both in the course of stope works and when maintaining the extraction mine workings (in case of the operational necessity) behind the stope face. The texture transformations in the studied zone lead to a sharp increase in the flexure strains of the thrust system as a whole without a significant change in the mechanical properties of the lithotype within the rock block itself; this is the fundamental difference of changes in the behaviour and properties of rocks and, for example, the zone of uncontrolled collapse.

Techniques for modelling the hinged-block displacement zone are as follows. Within the zone thickness, there is a differentiated division of each rock layer into blocks. The most reliable prediction of the zone thickness is expedient on the basis of stability analysis of the main roof rock layers with the use of mining-andgeological sections in the area of location, for example, of protecting pillars, as well as a gained experience in the stope works operations on this coal seam or series of strata. As a rule, the hinged-block displacement zone is propagated (in the Western Donbas conditions) to a height of $10-15 \mathrm{~m}$ and most often its top border is a very thin coal seam or interlayer, which has virtually no adhesion to either the overlying or underlying lithotypes. Thus, the thickness of the hinged-block displacement zone is assessed in each specific mining-engineering situation, but with the obligatory consideration of the weakening factors, such as water cut and fracturing which actively influence on the lithotypes stability.

On the practical level, each rock layer is being broken up into a number of blocks by tension cracks simulators, on the surfaces of which adhesion is completely absent, and the interaction of the blocks with each other is performed due to normal forces and shearing friction stresses. By means of this geometric construction, the adequacy is ensured of the process of thrusting the rock blocks due to the possibility of their repetition relative to each other: when maintaining the previous mechanical characteristics within the rock block, an increased deformability of the thrust system is realized at a level ten times higher than the flexure strain (without destruction) of the holistic rock layer.

The question remains relative to the geometrical parameters of the hinged-block displacement zone, which are recommended on the basis of existing concepts on the mechanism of the rocks displacement in the coaloverlaying formation with specification for the Western Donbas conditions in accordance with studies [19, 24-28]. To clarify the geometric parameters substantiation, the schemes are presented in Figure 2 of the hinged-block displacement zone propagation in two mutually perpendicular directions, for example, along the strike and to the dip (rise) of a coal seam. In the coal pillar cross section (along the strike of the seam), the hinged-block displacement zone is propagated to its depth by $12-20 \mathrm{~m}$ and blocks in each rock layer should be modelled over this distance. From the side of the mined-out space (previous periods of stope works operation), the hinged-block displacement zone is constantly present, but stabilization of the SSS components distribution occurs, as a rule, at a distance of $15-20 \mathrm{~m}$ due to the significant deformability of the thrust-block systems; therefore, with some margin, it is recommended to accept $Z=25-30 \mathrm{~m}$.

The blocks dimensions along the strike in each layer are different, and their value is partially chosen arbitrarily, based on the tendency: the greater the lithotype thickness, the more it is resistant to bending loads and is able to form rock cantilevers with an increased length. Moreover, the blocks length can be substantiated using a two-staged modelling technology [29, 30]: at the first stage, the SSS of holistic layers is studied and the areas of destructive stresses concentrations impact are determined, where the layer is most likely to be divided into blocks; at the second stage, the SSS of an already block system of all layers is calculated according to the thickness of the hinged-block displacement zone. However, this approach also has some uncertainty, since the curves of the SSS components distribution are changed quite smoothly. Hence, it is difficult to set (according to various criteria of discontinuity) the exact coordinate of the main crack location, which separates one or another lithotype.

At the same time, the studied ambiguity in the rock blocks dimensions has an insignificant influence on the rocks SSS of the hinged-block displacement zone. Such a conclusion has been made on the basis of multivariate SSS calculations of this zone, for example, [19], where its essence is revealed: the main peculiarity of the thrust systems is their yielding property - the layer rigidity is reduced tenfold, and the value of this decrease is relatively independent on the blocks dimensions, since the length of 
the thrust systems is at least an order of magnitude greater.

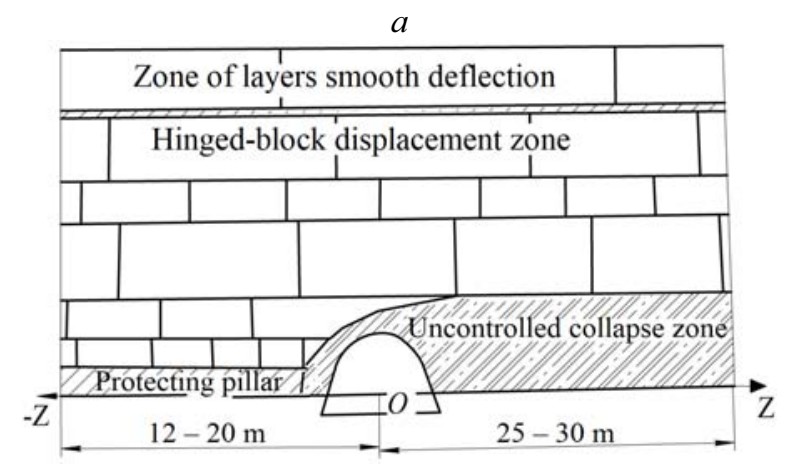

$b$

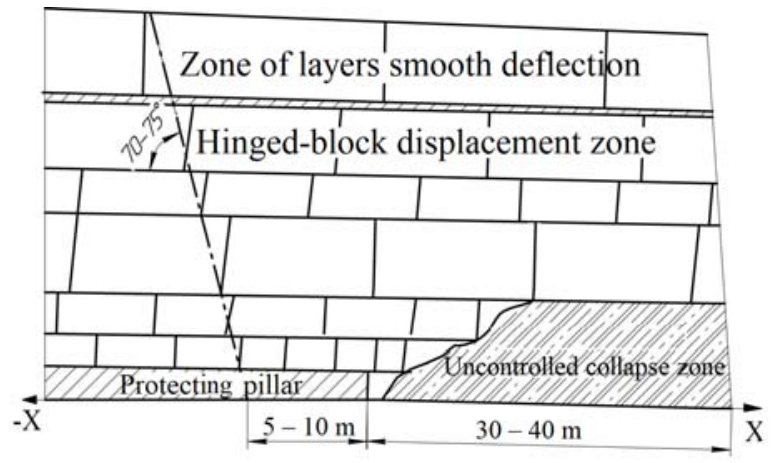

Fig. 2. Schemes for texture transformation of the coal-overlaying formation in a cross $(a)$ and longitudinal $(b)$ protecting pillar sections.

In the protecting pillar longitudinal section (for example, to the rise of the seam), the same principles to substantiate the block dimensions (usually from $2 \mathrm{~m}$ to $8 \mathrm{~m}$ ) are recommended with a different general tendency of the block length increase when removing from the coal seam. Here, according to [24-26], the maximum stresses concentrations in the former frontal bearing pressure zone are propagated to depth of a pillar by $5-10 \mathrm{~m}$. Over time, the line (by the coal-overlaying formation thickness) of their maxima is located at an angle of $70-75^{\circ}$ to the horizontal, which will be the boundary of the hingedblock displacement zone from the side of the seam rise. From the opposite side, the vast dimensions of the minedout space with a sufficiently constant texture of the hinged-block displacement zone make it possible to restrict the dimensions of its reflection to $30-40 \mathrm{~m}$.

Based on these parameters, it is recommended to construct geomechanical models of the massif initial state before mining the protecting pillars; in the process of their stope extraction, the dimensions should be increased to the peculiarities of modelling, previously indicated in the second paragraph. However, when calculating such models with vast sizes, provided that it is necessary to consider the structural transformations of adjacent roof rocks, one usually has to deal with a lack of computational resources and, for this reason, stop the calculation procedure.

The accumulated experience of modelling such geomechanical situation has led to two ways of its solution without significant damage to the calculation accuracy. The first way is to restrict the extension (in coordinates $X$ and $Z$ ) of the rock layers of the hingedblock displacement zone, where they are broken up into rock blocks; the sizes of these restrictions are shown in Figure 2. The second way is to break up into blocks only the lower layers of the zone, the number of which is determined experimentally by the criterion of the possibility to perform the calculation procedure. As for the remaining upper layers of the zone, the deformation modulus should be reduced by an order of magnitude for cumulative account of this technogenic fracturing in accordance with studies [31-33].

In general, modelling of the second, third, and fourth peculiarities of the protecting pillars extraction process will allow for acceptable (for mining-engineering calculations) adequacy of the real research object reflection and the reliability of the SSS calculation results of the coal-bearing massif.

Another group of geomechanics tasks related to the joint mining of two or three coal seams, quite reasonably uses (for constructing the models) the principles studied above, but taking into account the specifics of mining operations. Thus, in the works [17, 19], the following algorithm for performing a computational experiment:

- a coal-bearing stratum composed of holistic rock layers is modelled with a reflection of the uncontrolled collapse zone during extraction of an overlying coal seam; based on the results of the SSS calculation, the parameters of the hinged-block displacement zone of the main roof rocks and the block texture in the soil rocks of the overlying coal seam are substantiated;

- a geomechanical model is being constructed with a reflection of the roof and bottom rocks continuity of the overlying seam; the SSS of the entire coal-bearing stratum is calculated with the definition of the influence areas boundaries (on the underlying coal seam) of the rock pressure anomalies caused by the overlying seam extraction;

- the underlying coal seam extraction is modelled with the reflection of the uncontrolled collapse zone behind the longwall face, as well as all discontinuities caused by mining the overlying coal seam;

- according to the SSS calculation results from the previous stage, the parameters of massif discontinuities related to the underlying seam extraction are introduced. Then, the SSS of the coal-bearing stratum is calculated and analysed with an assessment of the degree of parting rocks stability;

- the final conclusion is made on the extent of the overwork influence on the state of the massif around mine workings of the lower horizon; the most dangerous areas along their length are determined and initial data are generated for constructing the geomechanical models of maintaining mine workings in the conditions of their overworking.

Thus, despite the significant differences in the tasks being solved in the two directions under study (extraction of protecting pillars and joint mining of coal seams in the suite), the principles for approaching their solution have a common implementation algorithm in terms of reflecting similar peculiarities of the coal-bearing massif discontinuities. The same common peculiarities exist for the final stage of research, which is formulated as the fifth 
peculiarity of the computational experiment - constructing a model, calculating the SSS and its analysis for the adjacent massif and the support of the overworked mine working. The peculiarity consists in the multi-scale modelling of the geomechanical "massif-support" system, because adequate reflection of the support elements (special interchangeable SCP profile of the frame support, roof-bolts, means for strengthening the fastening structures, etc.) requires finite elements mesh that differ by two - three orders from those for the adjacent massif.

The noted reason is decisive (in the conditions of a limited computational resource) for finding a compromise solution to the problem of failure-free computational experiment. The essence of the compromise is as follows. It is necessary to adequately reflect the real design of the fastening system of the overworked mine working for subsequent assessment of its elements state with a sufficient for practice reliability degree. A small-scale mesh of volume finite elements is required here. On the other hand, the loading of the fastening structure is conditioned by the surrounding rock massif deformation, where a larger-scale finite element mesh can be used, but with differentiation in reflection of different-sized texture peculiarities, including areas of discontinuity.

The model adequacy and the reliability of the SSS calculation results of the "massif-support" system will depend on the dimensions of the modelled massif surrounding mine working and the conditions of its loading at the borders. The general tendency is that, the larger the model dimensions, the less distortion in the fields of the SSS components distribution. Therefore, as a rule, it is necessary to perform several stages of calculating the SSS with a gradual decrease in the model dimensions (or, on the contrary, their increase) in order to search for such maximum permissible values, at which the calculation procedure stability within the available computational resource is still ensured.

When the maximum permissible model dimensions are determined, the borderline conditions of its loading are specified in the form of functions of vertical $\sigma_{y}(x, z)$, horizontal $\sigma_{x}(y, z)$ and $\sigma_{z}(y, x)$ stresses distribution along the model boundaries. These functions are determined from the calculation of the initial (general) model, which includes all the previously described peculiarities of mining-engineering situations of the protecting pillars mining or joint mining of coal seams in the suite.

Thus, the final peculiarity of modelling the fastening structure of overworked mine workings provides for the general two-staged performance of calculations:

- the first stage is a reflection of the mining-engineering situation as a whole using a geomechanical model with the required dimensions (it is sometimes called a "macro model") in a coal-bearing massif, but without reflection of mine workings fastening structure; insignificant error from such an assumption is substantiated, for example, in the works [34-36];

- the second stage - constructing of the so-called subordinate model with a detailed reflection of the fastening structure of the overworked mine working with the search for its maximum permissible dimensions; on the model bounds, the load functions are specified, determined when calculating macro model.
The calculation schemes and certain results of solution in one of the studied directions of the protecting pillars mining are given as examples of the proposed principles implementation for solving the geomechanics problems class on overworking of mine workings.

Figure 3 presents the macro model of mining the protecting pillar left in the previous periods of stope works along the seam $C_{6}$ in order to protect the underlying steepdipping ventilation crosscut No. 1 (SVC No. 1) located in the bottom of the seam $C_{5}+C_{5}{ }^{\text {top }}$ (MM "Dniprovske", PJSC "Pavlohradvuhillia", Ukraine). Such a miningengineering decision is conditioned by two reasons: moderate thickness of a parting and low strength characteristics of the constituent lithotypes, some of which are exposed to the active influence of weakening factors, namely, moisture saturation and fracturing. Now the task set is to assess the degree of the stope works influence in case of the protecting pillar extraction on the state of the SVC No. 1, the further maintenance of which ensures reliable functioning of ventilation systems in this area of the mine field.

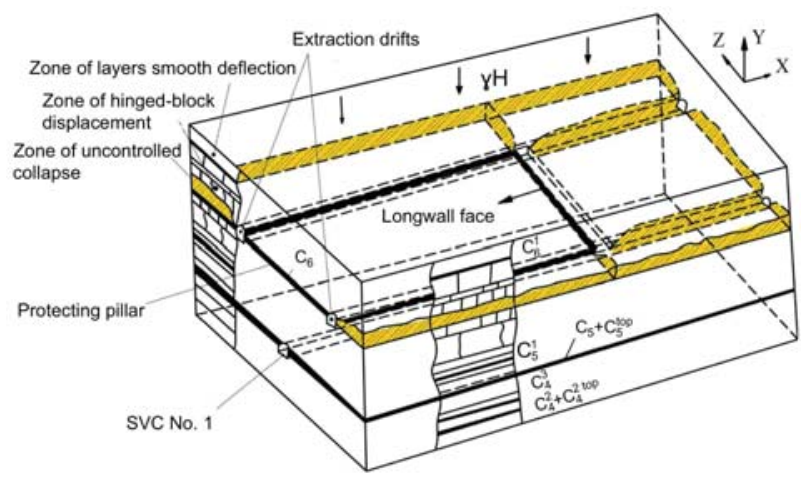

Fig. 3. Macro model of the protecting pillar extraction above the SVC No. 1.

The macro model (Figure 3 ) is being constructed with the maximum size along the strike (coordinate $Z$ ), although a sufficiently symmetric SSS components distribution is assumed here with respect to the axis $X$ drawn along the centre of the pillar width. Therefore, it is entirely permissible to consider only half of the macro model by the coordinate $Z$, which will significantly save the computational resource. It is appropriate to recall that when calculating the macro model, the fastening structure of the SVC No. 1 is not modelled, and the main task is to determine the fields of $\sigma_{y}, \sigma_{x}$ and $\sigma_{z}$ distribution around the SVC No. 1 at a distance of up to several tens of meters from it. These fields of the SSS components distribution serve as borderline conditions when constructing the subordinate model.

The subordinate model (Figure 4) has been constructed with account of a stage-by-stage search for its maximum permissible dimensions by the factor of failurefree computational experiment. As a result, its dimensions have been determined by the coordinates: $z=25 \mathrm{~m}$, $x=4.5 \mathrm{~m}, y=29.8 \mathrm{~m}$. The lower horizontal bound is modelled as a rigid base; on all other bounds, the loads are specified in the form of distribution curves $\sigma_{y}(x, z)$, $\sigma_{x}(y, z)$ and $\sigma_{z}(y, x)$ at the corresponding distances of the subordinate model boundaries from the contour of the 
SVC No. 1. In the mine working itself, the frame support is modelled (10 sets with a step of setting $0.5 \mathrm{~m}$ ) in full compliance with the technical documentation.

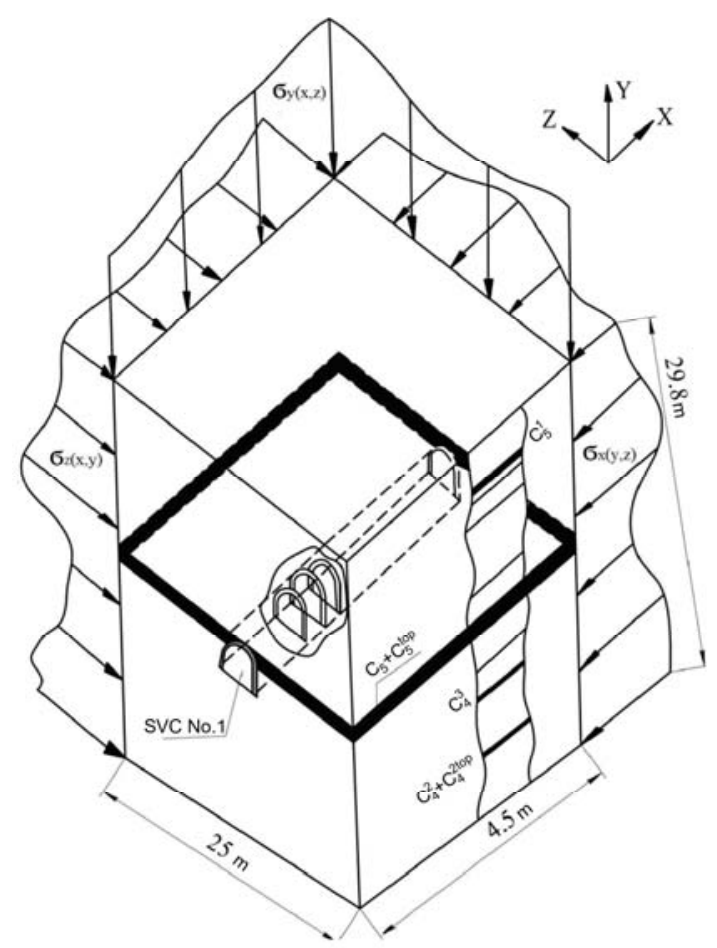

Fig. 4. Subordinate model for maintenance of the SVC No. 1.

The results of calculating the SSS of subordinate model can be illustrated by several options, for example, in the form of curves of the stresses components $\sigma_{y}, \sigma_{x}, \sigma_{z}$ distribution, as well as an integral indicator - stresses intensity $\sigma$. But, the distribution of the relative indicator $\sigma / \sigma_{\text {yield }}$ along the frame support contour is a more evident final result of the analysis performed. This indicator ( $\sigma_{\text {yield }}$ - the estimated yield limit of the SCP steel of the frame support) most informatively assesses the frame support state in terms of approaching the maximum permissible value $\sigma_{\text {yield }}$ or even exceeding this value.

On the practical level, according to the curve of the indicator $\sigma / \sigma_{\text {yield }}$ distribution, it is possible to judge about the areas of the frame contour that are in a stable state and, on the contrary, about the areas requiring the frame support strengthening. For example, Figure 5 shows that in the cap board of the frame, in the central part of the arch of $1.5-1.6 \mathrm{~m}$ long, the indicator $\sigma / \sigma_{\text {yield }}$ varies in the range of $64-85 \%$. This indicates a stable state in the central area of a cap board. At the same time, when approaching the peripheral areas of the cap board, the indicator $\sigma / \sigma_{\text {yield }}$ increases to $87-98 \%$, and in separate local intervals of length to $100-106 \%$. Consequently, the occurrence of the limiting state of SCP steel with the exhaustion of loadbearing capacity of the cap board is predicted here. Obviously, it is necessary to strengthen the peripheral areas in the cap board, for example, by setting a pair of oblique roof bolts in each side of mine working.

An even more dangerous state is along the length of the rectilinear part of the frame prop stays: the indicator $\sigma / \sigma_{\text {yield }}$ reaches $113-137 \%$ and characterizes the widespread occurrence of the limiting and superlimiting state of SCP steel (Figure 6).

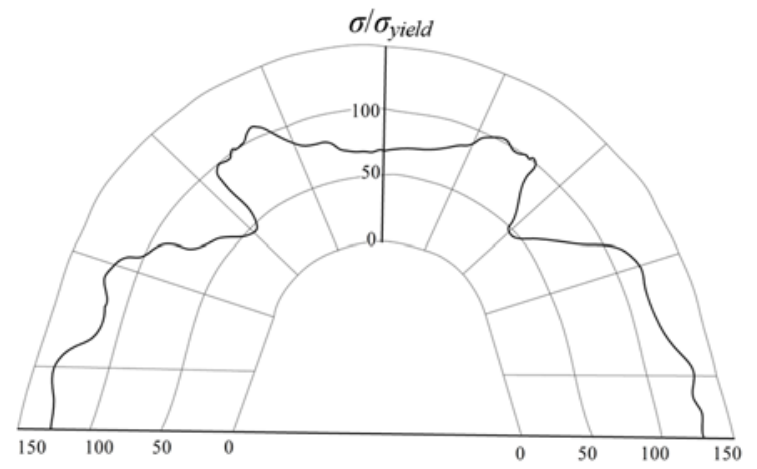

Fig. 5. Relative stresses intensity $\sigma / \sigma_{\text {yield }}$ distribution in the frame support of the SVC No. 1.
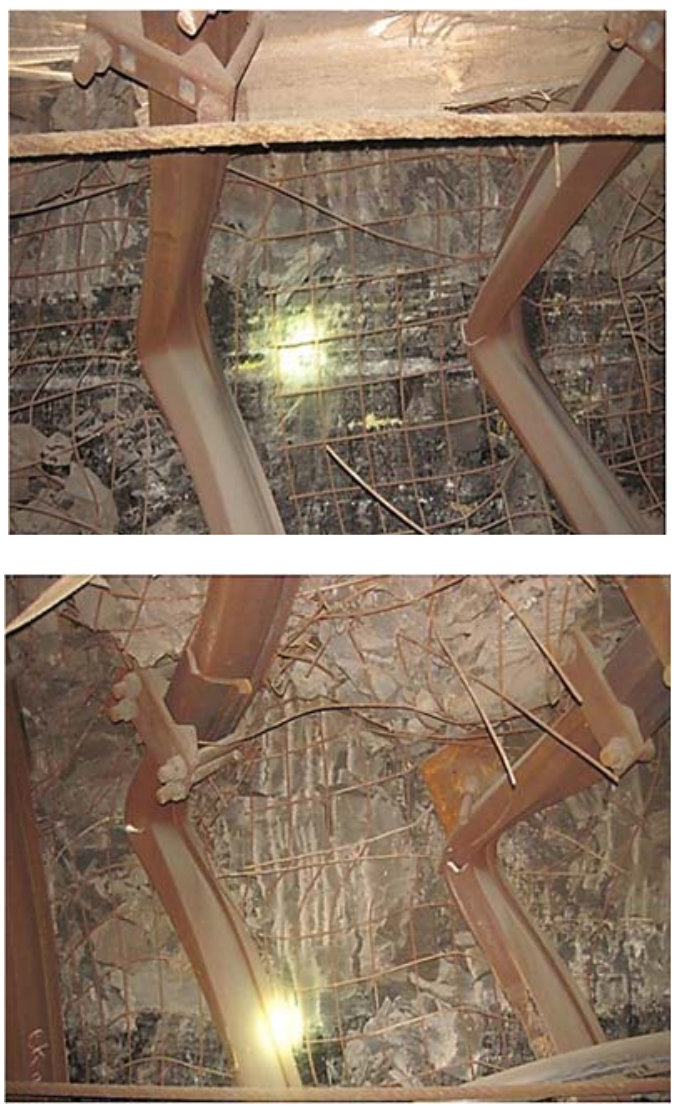

Fig. 6. Deformation of the frame stays.

This contributes to the loss of a stable form by the prop stays and the activation of their convergence with a significant reduction in the residual cross-sectional area [37]. It is also recommended to set predominantly horizontally directed roof bolts, strengthening the border lateral rocks; in addition, it is expedient to tie the tail joints of the roof bolts with the frame prop stays, which will effectively restrict their convergence (Figure 7).

Thus, using a specific example of the protecting pillar extraction, a structure has been developed for conducting a computational experiment from a macro model with vast sizes to the substantiation of practical recommendations for ensuring the overworked mine working stability. 


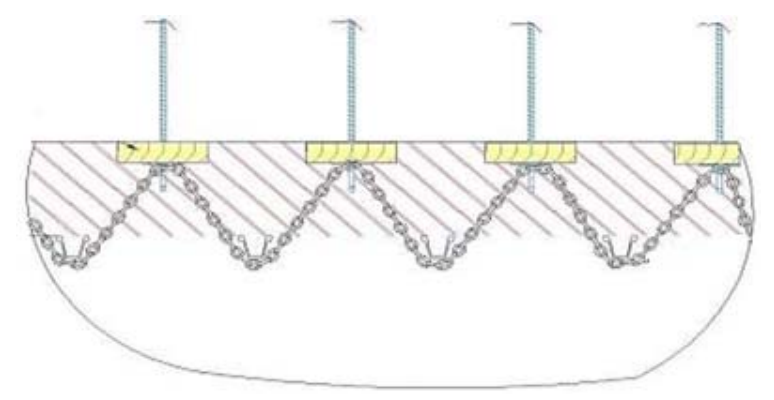

Fig. 7. Improvement of fastening technology.

\section{Conclusions}

1. The tasks of geomechanics on overworking of mine workings are distinguished by the sufficient complexity of reflecting the mining-and-geological and miningengineering situation adequately for three main reasons:

- the necessity of modelling a network of underground mine workings at different horizons of mining operations;

- it is required to consider the parameters of rock pressure anomalies (zones of bearing pressure and unloading) when mining an overlying coal seam. This determines not only the spatial problem setting, but also the significant model dimensions by all three its coordinates;

- the stope works, conducted at different periods on overlying coal seams, have led to radical transformations of some lithotypes texture of the coal-bearing stratum, which has a significant effect on its SSS as a whole and, therefore, requires adequate reflection in geomechanical models.

2. Five peculiarities of the geomechanical models construction on overworking of mine workings have been substantiated and revealed, the implementation of which predicts obtaining the reliable results for determining SSS within the accuracy sufficient for mining-engineering calculations.

3. A stage-by-stage algorithm is proposed for solving this class of problems, which differ in the scale of the modelled objects (the dimensions of volume finite elements vary by two or three orders of magnitude). The technology of sequential performance of a series of computational experiments to operate the parameters of the so-called macro model (reflects the studied object as a whole) has been substantiated, followed by obtaining the results for constructing and calculating a subordinate model. Here, the parameters of the overworked mine working and its fastening structure are reflected in full compliance with the technical documentation on conducting and exploitation of mine working.

4. An example is presented of the task solution of the protecting pillar influence of the overlying coal seam on the state of a mine working located in the underlying coal seam. The state of the overworked mine working support has been assessed and recommendations are formulated for its maintenance in operational condition.

The authors express their gratitude to the management of DTEK Coal Unit for their help in organizing the experimental research.

\section{References}

1. G. Pivnyak, V. Bondarenko, I. Kovalevs'ka, M. Illiashov (ed.), Geomechanical processes during underground mining (EDP, CRC Press, Taylor \& Francis Group, 2012). doi:10.1201/b13157

2. M. P. Zborshchik, V. V. Nazimko (ed.), Protection of the workings of deep mines in the de-stressed zone (EDP Sciences, Tekhnika, 1991)

3. B. Rahimi, M. Sharifzadeh, X.T. Feng, Ground behaviour analysis, support system design and construction strategies in deep hard rock mining Justified in Western Australian's mines. J. Rock Mech. Geotech. Eng. 12, 1 (2020). doi:10.1016/j.jrmge.2019.01.006

4. X.-T. Feng, J.A. Hudson (ed.), Rock Engineering Design (EDP, CRC Press, Taylor \& Francis Group, 2011). doi:10.1201/b11783

5. L. Jing, A review of techniques, advances and outstanding issues in numerical modelling for rock mechanics and rock engineering. Int. J. Rock Mech. Min. Sci. 40, 3 (2003). doi:10.1016/S13651609(03)00013-3

6. P. Malkowski, Z. Niedbalski, T. Majcherczyk, Roadway design efficiency indices for hard coal mines. AGG 13, 2 (2016) doi:10.13168/agg.2016.0002

7. P. Małkowski, Z. Niedbalski, J. HydzikWiśniewska, The Change of Structural and Thermal Properties of Rocks Exposed to High Temperatures in the Vicinity of Designed Geo-Reactor. Arch. Min. Sci. 58, 2 (2013). doi:10.2478/amsc-2013-0031

8. A. Begalinov, T. Almenov, R. Zhanakova, B. Bektur, Analysis of the stress deformed state of rocks around the haulage roadway of the Beskempir field (Kazakhstan). Min. Miner. Depos. 14, 3 (2020). doi:10.33271/mining14.03.028

9. Yu. M. Khalimendik, V.A. Nazarenko, A.V. Bruy, Yu.A. Zabolotnaya, Rock Pressure Problems 18, 104-115 (2010)

10. L. Qingha, S. Weiping, Y. Renshu, Deformation mechanisms in a coal mine roadway in extremely swelling soft rock. SpringerPlus 5, 1 (2016). doi:10.1186/s40064-016-2942-6

11. Y. Yuan, Z. Chen, C. Xu, X. Zhang, H. Wei, Permeability enhancement performance and its control factors by auger mining of extremely thin coal seams. J. Geophys. Eng. 15, 6 (2018) doi:10.1088/1742-2140/aae068

12. D. Yang, J. Li, Y. Wang, H. Jiang, Research on vibration and deflection for drilling tools of coal auger. JVE 19, 7 (2017). doi:10.21595/jve.2017.18581

13. C. Follington, I.L. Deeter, R. Share, D. Moolman, J. S. Afr. I. Min. Metall. 101, 1, 25-32 (2001)

14. S. Skipochka, Conceptual basis of mining intensification by the geomechanical factor. E3S Web $\begin{array}{llll}\text { of } & \text { Conf. } & \mathbf{1 0 9} & \text { (2019). }\end{array}$ doi:10.1051/e3sconf/201910900089 
15. K.S. Ishchenko, A.P. Krukovskiy, V.V. Krukovskaya, A.K. Ishchenko, Naukovyi Visnyk Natsionalnoho Hirnychoho Universytetu, 2, 85-91 (2012)

16. Q. Xu, Y. Li, J. Lu, L. Zhang, The use of surrounding rock loosening circle theory combined with elasticplastic mechanics calculation method and depth learning in roadway support. PLOS One 15, 7 (2020). doi:10.1371/journal.pone.0234071

17. V. Bondarenko, I. Kovalevska, O. Husiev, V. Snihur, I. Salieiev, Concept of workings reuse with application of resource-saving bolting systems. E3S Web of Conf. $\mathbf{1 3 3}$ (2019). doi:10.1051/e3sconf/201913302001

18. V. Lozynskyi, P. Saik, M. Petlovanyi, K. Sai, Ye. Malanchuk, Analytical Research of the StressDeformed State in the Rock Massif around Faulting Intern. J. of Eng. Res. in Afr. 35 (2018). doi:10.4028/www.scientific.net/JERA.35.77

19. I. Kovalevska, Z. Pilecki, O. Husiev, V. Snihur, Assessment of the mutual influence of deformationstrength characteristics of the fastening system elements. E3S Web of Conf. 123 (2019). doi:10.1051/e3sconf/201912301006

20. V.V. Nazimko, News of the Higher Institutions. Mining J. 10 (1981)

21. M. P. Zborshchik, V. V. Nazimko, Min. Miner. Depos. 73, 48-52 (1986)

22. P. Małkowski, Z. Niedbalski, T. Majcherczyk, Ł. Bednarek, Underground monitoring as the best way of roadways support design validation in a long time period. Min. Miner. Depos. 14, 3 (2020). doi:10.33271/mining 14.03.001

23. T.R. Stacey, In Absrtacts of the 8th Int. Symp. on Gr. Sup. in Min. and Under. Constr., Lulea University of Technology, Sweden (2016)

24. V. Bondarenko, I. Kovalevska, H. Symanovych, M. Barabash, V. Snihur, Assessment of parting rock weak zones under the joint and downward mining of coal seams. E3S Web of Conf. 66 (2018). doi:10.1051/e3sconf/20186603001

25. S. Prusek, S. Rajwa, A. Wrana, A. Krzemień, Assessment of roof fall risk in longwall coal mines. Int. J of Min., Recl. and Env. 31, 8 (2017). doi:10.1080/17480930.2016.1200897

26. M.V. Barabash, Dissertation, National Mining University, 2017

27. O. Krukovskyi, V. Krukovska, Yu. Vynohradov, Mathematical modeling of unsteady water filtration into anchored mine opening. Min. Miner. Depos. 11, 2 (2017). doi:10.15407/mining11.02.021

28. P. Małkowski, Z. Niedbalski, T. Balarabe, A statistical analysis of geomechanical data and its effect on rock mass numerical modeling: a case study. Int. J. Coal Sci. Technol. (2020). doi:10.1007/s40789-020-00369-2

29. M. Salcher, R. Bertuzzi, Results of pull tests of rock bolts and cable bolts in Sydney sandstone and shale. Tunnel. and Und. Sp. Tech. 74 (2018). doi:10.1016/j.tust.2018.01.004

30. O.A. Tsikra, Dissertation, Institute of Geotechnical Mechanics named by N. Poljakov of National Academy of Sciences of Ukraine, 2010

31. K.V. Ruppeneyt (ed.), Deformability of fractured rock mass (EDP Sciences, Nedra, 1975)

32. M.M. Protod'yakonov, S.Ye. Chirkov (ed.), Fracturing and strength of rocks in massif (EDP Sciences, Nauka, 1964)

33. M.V. Rats, S.N. Chernyshov (ed.), Fracturing and properties of fractured rocks (EDP Sciences, Nedra, 1970)

34. P. Małkowski, T. Majcherczyk, Z. Niedbalski, In Absrtacts of the 22nd World Min. Cong., Istanbul, Turkey, 2011

35. V. Diomin, N. Nemova, M. Akhmetzhanov, S. Dvuzhilova, Naukovyi Visnyk Natsionalnoho Hirnychoho Universytetu, 1, 39-43 (2017)

36. O. Voloshyn, O. Ryabtsev, Studies of stationary supporting zone sizes varied in the course of mining operations in deep horizons. Ann. Sc.-Tech. Coll. Min. Miner. Depos., 71-76 (2013). doi:10.1201/b16354-13

37. R.M. Svystun, Dissertation, National Mining University, 2014 